\title{
Evaluating an Investment Opportunity Under Risk and Uncertainty Environment: A Case Study About Profitability and Risk in Desert Farming at Najed Area
}

\author{
Kheiry Hassan M. Ishag ${ }^{1,2}$ \& Hag Hamad Abdelaziz ${ }^{1}$ \\ ${ }^{1}$ Department of Agricultural Economics, Faculty of Agricultural Studies, Sudan University of Science and \\ Technology, Sudan \\ ${ }^{2}$ Dhofar Cattle Feed Company, Oman \\ Correspondence: Kheiry Hassan M. Ishag, Dhofar Cattle Feed Company, Oman. PhD candidate, Department of \\ Agricultural Economics, Faculty of Agricultural Studies, Sudan University of Science and Technology, Sudan. \\ E-mail: Kheiryishag@hotmail.com
}

Received: August 4, 2014 Accepted: September 7, 2014 Online Published: October 12, 2014

doi:10.5539/sar.v3n4p96 URL: http://dx.doi.org/10.5539/sar.v3n4p96

\begin{abstract}
Fodder is continuously cultivated in coastal area of Salalah and Batinah region of Sultanate of Oman. However, this created a negative impact on the overall agriculture system and production. The government authority stopped the cultivation of Rhodes grass in coastal area and support farmers with incentive systems in order to increase fodder production investment at Najed area. Due to irrigation water policy regulations, new technical solutions required, underground water availability, fodder investors have little data to help in making investment decisions. In addition, fodder production investments are characterized by much uncertainty due to the nature of the desert farming which is relying on many factors that cannot be controlled. In this paper a dynamic evaluation model was formed and developed as a method of analyzing the economic feasibility of fodder cultivation investment project with regard to project profitability under risk environment. Economic feasibility of the investment is evaluated through calculation of the Net Present Value and IRR by using Monte Carlo Simulation models. Our objective is to formulate a dynamic programming simulation model for the investment decision with incorporating this uncertainty in a probabilistic manner. Our simulation model result shows that the dynamic models are able to help investors and policy makers in taking optimum investment decision. Taking the risk into account leads to a significant decrease of the economic attractiveness of stakeholders and more Government support is needed to achieve water policy objectives and project sustainability at new developed area at Najed.
\end{abstract}

Keywords: Rhodes Grass, investment project, economic efficiency, simulation model, risk and uncertainty

\section{Introduction}

The Net present value (NPV) is the most common method in investment evaluation (Wang, 1998). Alkaraan and Northcott (2006) have analyzed the use of conventional investment appraisal techniques such as payback period, return on assets, return on investment (ROI), internal rate of return (IRR), NPV and risk analysis approaches such as sensitivity analysis, adjustment of the payback period, or discount rate. Incorporating risk and uncertainty analysis in projects is currently one of the main topics of interest for researchers and practitioners working in the area of project investment decision making (Savvakis \& Savvides, 1994; Omer, 2008).

Agricultural farmers and landowners in the Al-Batinah and Salalah plains exploiting the good ground water resources took to wide scale cultivation of Rhodes Grass which is easy to grow and crop can be taken out at least six times a year. The excessive use of the precious freshwater has led to ingression of salinity in the area (Water Science and Technology Association, 2010). This poses a grave threat to the ecosystem. The Ministry of Agriculture and Fisheries (MAF) was seized of this problem and carried out an exercise to solve the problem, at the same time meeting the fodder requirements of the livestock to match the needs of a growing population. The (MAF) decided to gradually stop the cultivation of Rhodes Grass in Al-Batinah and Salalah plains and at the same time develop substitute areas in the Najed to meet the fodder requirement.

More specific fodder production depends on the availability of irrigation water from underground at new 
developed area at Najed. Farming in this area influenced by activities of farmers and farmers involvements in the water management; the interdependence creates difficulties to predict expected amount of irrigation water and increases complexity in decision making in crop and water allocation. Moreover, producers must also cope with yield uncertainties caused by underground water availability, diseases and pest damages and price uncertainties caused by changes in markets as well (Quiroga, Fernandez-Haddad, \& Iglesias, 2010).

Water requirements for crops in Najed area are fulfilled by underground water. As a result, the availability of water depends on natural as well as human and policy factors. The excessive use of underground water might affect the availability of irrigation water in Najed Area in Oman and affect farming sustainability and cause environment problems. This paper investigated the appropriate methodology of project feasibility with underground water drawdown risk with and without water recharge.

The Ministry of Regional Municipalities, Environment and Water Resources (MRMEWR) announced new water policy and advised the allowed quantities of water to be extracted out in the project area at Najed. The total quantity of water allowed to be extracted should not exceed 112 million cubic M/year and water extraction per well restricted to $30 \mathrm{Lit} / \mathrm{Sec}$ only. Moreover, the (MRMEWR) determined the distance and spacing between wells at project area should not be less than $1 \mathrm{KM} \mathrm{X} 1 \mathrm{KM}$ so that water flow should not be affected. Along with this new water policy the (MAF) decided to stop cultivation of Rhodes Grass in Al-Batinah and Salalah plains to cope with salinity problem and uncertainty caused by underground irrigation water supply which gained attention as one of the main subjects needing to be addressed following the drought years in Oman. Government also decided to encourage privet investors to develop Najed Area by giving lands to farmers and give capital grants to privets project to achieve financial sustainability. However, the sustainable development of Najed Area should meet the needs of the present without compromising the ability of future generations to meet their own needs.

The application of new water policy will increase capital and operation cost and includes uncertainty factors which will affect economic efficiency of the resources. The risk and uncertainty are best thought of as representing a spectrum of unknown situations with which an analyst may be dealing, ranging from perfect knowledge of the likelihood of all the possible outcomes at one end risk to no knowledge of the likelihood of possible outcomes at the other uncertainty (Monacciani, 2011).

It is not the real-world situation itself, which is either risky or uncertain, but merely the information available to analysts, which defines it as such. All actual project outcomes are unknown, because they occur in the future and are subject to influence by a number of variables, each of which may take different values (James et al., 2007). If we have reliable historical or forecast data such that a probability distribution can be constructed for such variables, the situation can be modeled as risky. If we do not have such data we can only describe the future in terms of uncertainty. The range of crop yield treated as risky and underground water availability treated as uncertainty in our model.

A quantitative risk analysis can be performed a couple of different ways. One way uses single-point estimates, or is deterministic in nature. Using this method, an analyst may assign values for discrete scenarios to see what the outcome might be in each. For example, in a financial model, an analyst commonly examines three different outcomes i.e. the worst case, best case, and most likely case. In conventional analysis, there are several problems with deterministic approach analysis as it considers only a few discrete outcomes and ignoring hundreds or thousands of others. It also gives equal weight to each outcome and ignores the interdependence between inputs, and impact of different inputs to the outcome (Asian Development Bank, 2002).

Monte Carlo Simulation models were used in this study to quantify risk and uncertainty in desert farming at Najed Area. The quantitative risk analysis will provide decision makers a means of estimating the probability that the project NPV will fall below zero, or that the project IRR will fall below the opportunity cost of capital (David, 2004). The model will also help in improving water management policy and achieve two objectives simultaneously: sustaining irrigated agriculture for food security and preserving the associated natural environment.

\section{Methodology}

The project evaluation first task is to estimate the future values of the projected project variables by using available information regarding a specific situation of the past to predict a possible future outcome of the similar project. The approach normal used in investment appraisal is to calculate a "best estimate" based on the available data and use it as an input in the evaluation project model. The single value estimate is usually the most likely outcome (NPV) or (IRR). 
The dynamic simulation model based on Net Present Value (NPV) and Internal Rate of Return (IRR) were used for evaluation of project feasibility of fodder crop growing at Najed Area and compared with the conventional NPV calculation method. The stochastic budgeting and stochastic efficiency methods are used to consider risk and uncertainty variables in the model presented in study (Gill, 2002; Botterud \& Korpa, 2007).

\subsection{Net Present Value}

The NPV was used as an evaluation criterion. The net cash flow, calculated by subtracting the cost from the revenue, was discounted by the interest rate to obtain the NPV of the project. If NPV is a function of all both deterministic and stochastic variables, the resulting NPV gets a range of values instead of a single value obtained in a conventional deterministic financial evaluation. NPV is obtained from the below formula.

$$
N P V=\sum_{n=0}^{N} \frac{C_{n}}{(1+r)^{n}}
$$

Where,

$\mathrm{ci}=$ the net cash flow in year $\mathrm{n}(\mathrm{n}=0,1,2, \ldots . \mathrm{n})$, represented by farm income in this study.

$\mathrm{n}=$ the planning period which equals twenty years in the current analysis.

$r=$ the discount rate.

\subsection{Monte Carlo Simulation}

Monte Carlo simulation is a computational algorithm designed to evaluate the variability or stochastic of the input variables of a model. It can be used to model the effects of key variables on the NPV of a given proposal. The process involves, first, the identification and assessment of the key variables. For each key variable, we fit a probability density function that best describes the range of uncertainty around the expected value. For this purpose, we used historical data at growing area and data from MAF and agriculture research center. The model including these variables is then calculated using randomly-generated input values taken from the underlying probabilistic distribution function. The computer model combines these inputs to generate an estimated outcome value for (NPV) and (IRR). The process is repeated (ten thousand times).

Monte Carlo simulation model is currently regarded as the most powerful technique for cash-flow analysis. It is useful when there are many variables with significant uncertainties. The more complex the project and the more risks and uncertainty that are associated, the more valuable Monte Carlo simulation analysis will be (Qiu, 2001).

Firstly a dynamic, stochastic simulation model of a Rhodes Grass farming was developed to evaluate the economics of investments in desert farming. The model was designed to characterize agriculture parameters and economical complexities of a Rhodes Grass farming within a partial budgeting framework by examining the cost and benefit streams coinciding with investment in desert farming and high risk areas. A secondary aim was to develop the model in a manner conducive to future utility as a flexible, farm-specific decision making tool. The basic deterministic model was constructed in Microsoft Excel 2010 (Microsoft, Seattle, Washington). The @ Risk 5.7 (Student Version for Academic Use) from (Palisade Corporation, Ithaca, New York) add-in for Excel was utilized to account for the stochastic nature of key variables in the Monte Carlo simulation model.

\subsection{Model Structure}

The modeling process began by defining a series of inputs to describe the initial status and behavior of the farm system. The underlying behavior of the Rhodes Grass growing system was represented using current knowledge and recorded data from MAF and literature. The purpose of qualitative risk analysis in this study is to provide a high level of understanding of risks of the project. Such analysis may increase attention of project management and water policy team members to the top risks they need to manage effectively.

The main risk and uncertainty variables identified in Najed Project were:

- Project capital increase and it is effect on NPV and IRR.

- Underground water availability and it is effect on crop yield and NPV and IRR.

- Crop selling price volatility and it is effect on NPV and IRR.

- Cost of production per ton and it is effects on NPV and IRR.

- Annual increase in sales price and unit cost.

- Total sale volume for year one of the project. 
- Irrigation water policies and it is effect on crop yield and NPV and IRR.

- $\quad$ Rhodes Grass crop yield variation at 3 proposed project locations.

The qualitative risk assessment performed after identified risk parameters by estimating the following:

- Risk probability of occurrence of each parameter.

- Risk impacts on project objectives such as capital cost- operation cost - crop yield and irrigation water policy - project sale volume and revenue. The risk impact built in a probabilistic model during quantitative evaluation.

The quantitative risk analysis is performed after selecting parameters and the probability and consequence of all individuals risk combined on parameters affecting the project financial performance and cash flows. The result of the analysis includes a probability that a project will meet its quantitative objectives and cash flow projection. All probability distribution of the parameters are incorporated in to Monte Carlo Simulation Model which allows evaluation and quantified risks range as shown in Table 1.

Table 1. Input parameters distribution used in MCS Models

\begin{tabular}{lllll}
\hline Variables & Distribution & Min & Mean & Max \\
\hline $1^{\text {st }}$ year yield with water decrease & Normal & - & 65286 & - \\
$1^{\text {st }}$ year yield without water decrease & Normal & - & 84630 & - \\
Annual increase in yield & Triangle & $2 \%$ & $3 \%$ & $5 \%$ \\
Sale price range year 1 & Triangle & 90 & 95 & 100 \\
Unit cost price year 1(\% sale price) & Triangle & $75 \%$ & $79 \%$ & $83 \%$ \\
Annual increase in price and unit cost & Triangle & $1 \%$ & $2 \%$ & $3 \%$ \\
Water reduction probabilities test & RiskBinomial & 0.1 & 0.5 & 0.9 \\
\hline
\end{tabular}

The study run 6 Stochastic Monte Carlo Simulation Models to evaluate the following:

- The difference between conventional and stochastic MCS model techniques for project investment evaluation and underground water risk assessment.

- The government incentive program that can reduce risk and uncertainty impacts of Najed Agriculture Development Project.

- The effect of irrigation water policy on crop yield and project NPV and IRR.

This section presents the model variables in coastal and desert areas. Desert farming area received government incentive to encourage farmers to develop Najed area. In addition to (Salalah) location with no water shortage, there were two location scenarios tested representing two water levels. Parameters used in the Salalah scenario and Najed area scenario reflects an expected water policy, capital cost, crop yield, total sale volume, sale price and per unit cost of production for each location. 
Table 2. Stochastic variables affect project NPV and IRR at different locations

\begin{tabular}{llll}
\hline Location & Salalah & Hanfeet & Dawkah \\
\hline Farm Location & Costal Farming & Desert Farming & \\
\hline Total required Farm Area/Ha & 1500 & 4200 & 3600 \\
Cultivated Area/Ha & 878 & 878 & 770 \\
Total Capital Budget RO & 4791524 & 7596000 & 7430000 \\
Government Incentive RO & - & 2599000 & 2543000 \\
Yield range Ton/Ha & $24-22$ & $24-22$ & $22-20$ \\
\% yield reduction due water level reduction & $1-3-5$ & $1-3-6$ & $2-5-7$ \\
Operation cost RO/ton & 58 & 75 & 79 \\
Unit cost year1/(\% of sale price) triangle dist. & $65-68-70$ & $75-79-83$ & $80-84-88$ \\
Annual increase in sale price \& unit cost \% & $1-3-5$ & $1-3-4$ & $1-3-5$ \\
Sale Price /ton (triangle distribution) RO & $90-95-100$ & $90-95-100$ & $90-95-100$ \\
Authorized Water discharge Mm ${ }^{3}$ & Un-limit & 31 & 25 \\
Water discharge in study Mm ${ }^{3}$ & Un-limit & 28 & 25 \\
No Wells & 20 & 40 & 35 \\
No central Pivots & 20 & 40 & 35 \\
Area per Central Pivots/ha & 40 & 22 & 22 \\
\hline
\end{tabular}

The following section describes the stochastic variables used in the model. The stochastic variables used in the farm location evaluation models are: Water level drawdown - increase in capital cost of the project due to new water policy at Najed project area- increase in operation cost (unit cost as a \% of sale price) - sale price annual \% increase in unit cost / sale price- annual \% yield reduction due to water level drawdown- the range of the crop yield per hectare and 1st year crop yield. The estimation of each input variable and probability distribution at each location identified and incorporated in the analysis.

Random sampling is used to estimate empirical cumulative distributions for the key variables. The probability distribution is a distribution of all possible values associated with a stochastic variable. A probability density function (PDF) represents the complete distribution of a stochastic variable and empirically measures values of the random variable producing a histogram depicting relative frequencies of output ranges, this histogram resembles the random variable's probability density.

\subsection{Research Displaying Scenarios}

For our case evaluation of the Najed Project we use three different scenarios e.g. Basic model - farm production without risk of underground water reduction, farm production with the risk of water reduction at year one without underground water recharges and farm production with the risk of water reduction at any year with a possibility of underground water recharges. Each scenario tested with and without government subsidy and from these scenarios we build two models for each scenario. 
Table 3. Research scenarios and models

\begin{tabular}{|c|c|c|c|}
\hline Scenarios & Water Risk level & G. Subsidy & Models \\
\hline \multicolumn{4}{|l|}{ (1) Basic Model } \\
\hline \multirow[t]{3}{*}{ Scenario One } & No water risk & & \\
\hline & Basic Model Najed Project & without & 1 \\
\hline & Basic Model Najed Project & with & 2 \\
\hline (2) Scenario Two & Water risk level 1 & & \\
\hline \multirow[t]{2}{*}{ (No water recharge) } & Basic Model Najed Project & without & 3 \\
\hline & Basic Model Najed Project & with & 4 \\
\hline (3) Scenario Three & Water risk level 2 & & \\
\hline \multirow[t]{2}{*}{ (With water recharge) } & Basic Model Najed Project & without & 5 \\
\hline & Basic Model Najed Project & with & 6 \\
\hline
\end{tabular}

\section{Result and Discussion}

\subsection{Static Location Model}

The static and deterministic models were performed to calculate the NPV and IRR of a project and quantify project feasibility. In financial theory, if there is a choice between two exclusively independent alternatives, the one with the higher NPV should be selected. The NPV and IRR calculated for three farm locations to compare coastal farm and new farm location at Najed area. The NPV of Salalah and Hanfeet location were positive and accordingly the investment opportunities were acceptable. A summary of the three farm location and the relevant values of NPV are given in Table 4. The second performance indicators used in this section are IRR or equity provider. The equity providers (also called sponsors) are generally focused on the project internal rate of return (IRR) which represents the yield of a project regardless of the financing structure.

Internal Rates of Return provide evaluation of the desirability of projects; the higher the IRR for a project, the better from an equity provider's perspective. Therefore equity provider use risk management policies to mitigate the potential impacts on this internal rate of return (IRR). The results of IRR analysis for three farm locations are given in Table 4. The analysis tests the Government capital subsidies to Hanfeet and Dawkah farm locations. The Government subsidy and grants for Hanfeet and Dawkah locations are deducted from project capital cost to test subsidy effect on NPV and IRR. Salalah Farm location is tested with tow deferent raw materials cost (with subsidy and without subsidy). 
Table 4. Cost of production per year of Rhodes Grass for three farm locations

\begin{tabular}{|c|c|c|c|c|}
\hline \multirow[t]{2}{*}{ Item } & \multirow{2}{*}{$\begin{array}{l}\text { Salalah } \\
\text { Coastal Area }\end{array}$} & Hanfeet & Dawkah & \multirow{2}{*}{$\begin{array}{l}\text { Difference } \\
\text { Hanfeet-Salalah }\end{array}$} \\
\hline & & \multicolumn{2}{|c|}{ New Location at Najed } & \\
\hline Cultivated area/ha & 878 & 878 & 770 & 0 \\
\hline Capital cost & 4791524 & 7596000 & 7430000 & 2804476 \\
\hline Revenue & 2502300 & 2502300 & 1975050 & 0 \\
\hline Raw material cost & 378418 & 506167 & 443905 & 127749 \\
\hline Land rent & 18000 & 50400 & 43200 & 32400 \\
\hline Utilities cost & 131700 & 173844 & 152460 & 42144 \\
\hline Vehicle running cost & 31608 & 40388 & 35420 & 8780 \\
\hline Overhead cost & 70240 & 140480 & 123200 & 70240 \\
\hline Labour cost & 93132 & 93132 & 93132 & 0 \\
\hline Misc expenses & 30730 & 30730 & 26950 & 0 \\
\hline Total variables cost & 753828 & 1035141 & 918267 & 281313 \\
\hline Administration Salary & 140166 & 202566 & 93366 & 62400 \\
\hline Administration cost & 65850 & 65850 & 57750 & 0 \\
\hline Depreciation cost & 369787 & 572000 & 495600 & 2022013 \\
\hline Finance cost & 240000 & 87120 & 85200 & -152880 \\
\hline Tax & 137120 & 71609 & 45608 & -65511 \\
\hline Total Overhead cost & 952923 & 999145 & 777524 & 46222 \\
\hline Net profit & 795549 & 468014 & 279259 & -327535 \\
\hline NPV RO & 2878601 & -2895923 & -3793210 & 17322 \\
\hline IRR & $18 \%$ & $3 \%$ & $-1 \%$ & $-15 \%$ \\
\hline
\end{tabular}

The static and deterministic models performed dos not considers underground water drawdown risk factors and its effects on project viability. The interaction of underground water level, water recharge and Government subsidy programs were not also incorporated in deterministic models.

\subsection{Stochastic Simulation Location Model}

The results of each scenario contribute to the decision making process as they shed light on the potential positive and negative economic and ecological implications of proposed water policy changes. The main parameters changed among the different simulations are presented in Table 2 and a full description of each scenario is presented in the subsequent paragraphs. Each scenario was ultimately designed to understand two primary effects: firstly, changes to project yield and income and the risk of Rhodes Grass production. Secondly, changes in underground water availability and its effect on yield and NPV.

Three Probabilities of water reduction were tested $(0.1-0.5-0.9)$ by using Risksimtable Function. Scenario one without underground water risk factor, Scenario two with underground water risk factor and no water recharge, and Scenario three with underground water risk factor and water recharge. The model simulation produces a range of possible outputs NPV and IRR represented in cumulative probability distributions addressing a level of $90 \%$ confidence for each different outcome. The results of the analysis presented in Tables 5 and 6.

The Government of Oman recommended a financial support to Najed Project. The Government provided a grant of RO 11.26 Million to support internal infrastructure to compensate capital cost increased and reduce the effect of project overrun. Capital costs of the project increased from 16 Million Rials to 22.8 Million Rials at the stage of face one of the project implementation. Face three at Wadi Bani Khawtar of a total capital cost 7 Million Rials has been postponed. Project cost overrun also affected NPV and has been incorporated in the models. The research also investigated if Government support sufficient enough and can cover the stochastic variations of 
future operation risk and project overrun risk. The Government subsidy program evaluated and tested within 3 scenarios and 6 MCS Models runs. The statistics result of the probability distribution of NPV and IRR for each model presented in below in Table 5 and 6.

Tables 5 and 6 present the minimum, mean, maximum, CV, and range for NPV for each project location and water availability scenario. Salalah location with sufficient underground water has minimum, mean, and maximum NPVs of R.O. -52 million, -10 million, and 28 million, respectively. These NPVs are all higher than the minimum, mean, and maximum for Hanfeet and Dawkah location at new developed area at Najed. With Government support program Hanfeet location (which represents underground water drawdown) returned simulated NPVs of R.O. - -40 million, -1.6 million, and 35 million for the minimum, mean, and maximum. Under underground water re-charged scenario model (6) result has minimum, mean, and maximum NPVs of R.O. -29 million, R.O. 0.122 million, and R.O. 29 million. With Government support the range has been reduced and Salalah location had the highest range while the Najed area had the lowest range of all four scenarios. The simulated relative risk is comparable in Hanfeet and Dawkah location. The relative risk is higher in the new developed Najed area because there is greater variability in the cost and yield per hectare of Rhodes grass crop. The analysis shows an improvement in NPV and IRR with Government support and subsidy programs. The expected loss ratio also reduced with Government subsidy.

Tables 5 and 6 also indicate statistical measures used to test different normal and non-normal risks associated with investing in Najed Project. The statistical analyses performed in this study are measure of central tendency which test the mean and mode of the NPV and IRR - measure of variability which test the stander deviation, variance and coefficient of variation of the models and the measure of Skewness and Kurtosis for each model.

The Skewness is a measure of the degree of asymmetry of a frequency distribution of investment return NPV and IRR, whereas, Kurtosis is a measure of the peakedness of the probability distribution or measures the degree of fat-tailness of the investment returns.

Table 5. Statistics of Models run results - without Government subsidy

\begin{tabular}{|c|c|c|c|c|c|c|}
\hline Models & Model (1) & Model (3) & Model (5) & Model (1) & Model (3) & Model (5) \\
\hline Item & NPV & NPV & NPV & IRR & IRR & IRR \\
\hline Mean Million RO & -10 & -13 & -11 & $-1 \%$ & $-3.2 \%$ & $-3 \%$ \\
\hline Mode & -13 & -17 & -15 & $3 \%$ & $2 \%$ & $3 \%$ \\
\hline SD & 9.989 & 9.943 & 7.128 & $11.5 \%$ & $11.6 \%$ & $10.0 \%$ \\
\hline $\mathrm{CV}$ & $0.99 \%$ & $0.76 \%$ & $0.65 \%$ & $11.5 \%$ & $3.63 \%$ & $3.33 \%$ \\
\hline Variance & 9.978 & 9.887 & 5.081 & 0.0133 & 0.0135 & 0.0092 \\
\hline Skewness & 0.0575 & 0.0434 & 0.0788 & -0.530 & -0.436 & -0.647 \\
\hline Kurtosis & 3.142 & 3.069 & 3.175 & 3.220 & 2.955 & 3.531 \\
\hline Min & -52 & -52 & -44 & $-38 \%$ & $-38.6 \%$ & $-38.0 \%$ \\
\hline Max & 28 & 22 & 16 & $31.3 \%$ & $27.3 \%$ & $23.0 \%$ \\
\hline Range & 80 & 74 & 60 & 69 & 66 & 61 \\
\hline Expected loss ratio & 0.65 & 0.70 & 0.73 & 0.55 & 0.57 & 0.62 \\
\hline
\end{tabular}


Table 6. Statistics of Models run results - with Government subsidy

\begin{tabular}{|c|c|c|c|c|c|c|}
\hline Models & Model (2) & Model (4) & Model (6) & Model (2) & Model (4) & Model (6) \\
\hline Item & NPV & NPV & NPV & IRR & IRR & IRR \\
\hline Mean Million RO & 1 & -1.6 & 0.122 & $13 \%$ & $9.45 \%$ & $10 \%$ \\
\hline Mode & 3.5 & -0.887 & -0.889 & $11 \%$ & $18 \%$ & $12 \%$ \\
\hline SD & 9.940 & 9.974 & 9.511 & $17 \%$ & $16 \%$ & $13 \%$ \\
\hline $\mathrm{CV}$ & $9.94 \%$ & $6.23 \%$ & $79.26 \%$ & $1.31 \%$ & $1.70 \%$ & $1.30 \%$ \\
\hline Variance & 9.881 & 9.948 & 9.046 & 0.024 & 0.028 & 0.0167 \\
\hline Skewness & 0.046 & 0.0736 & 0.0929 & -0.342 & -0.274 & -0.498 \\
\hline Kurtosis & 3.094 & 3.095 & 3.210 & 3.097 & 2.958 & 3.430 \\
\hline Min & -38 & -40 & -29 & $-37.3 \%$ & $-38.6 \%$ & $-38 \%$ \\
\hline Max & 41 & 35 & 29 & $66.5 \%$ & $59 \%$ & $48 \%$ \\
\hline Range & 79 & 75 & 58 & 103 & 98 & 86 \\
\hline Expected loss ratio & 0.48 & 0.53 & 0.50 & 0.36 & 0.39 & 0.44 \\
\hline
\end{tabular}

Figures (1-2-3-4-5-6) below provide the detailed SMCS models run results with and without Government scenarios. The coefficient of variation is a useful summary measure of project risk. It is the standard deviation of the projected returns divided by the expected value. Assuming a positive expected NPV and IRR value, the lower the coefficient of variation the less the project risk. Model 5 and model 3 without Government subsidy present a low variation coefficient $(\mathrm{CV})$ while model 1,2 and 6 with no water reduction have a high variability.

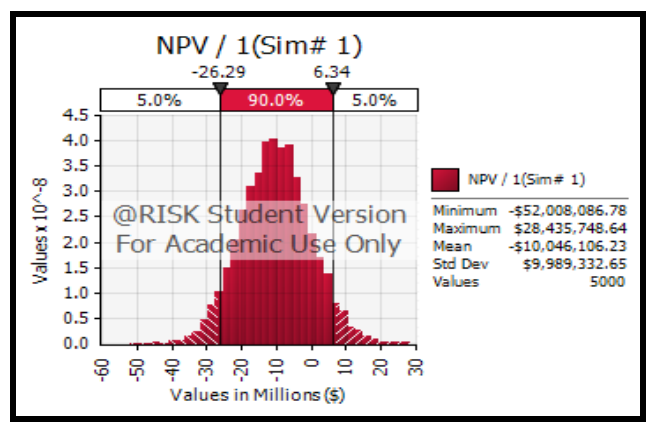

Figure 1. Model (1) SMCS Model

(without GS \& without water reduction effect)

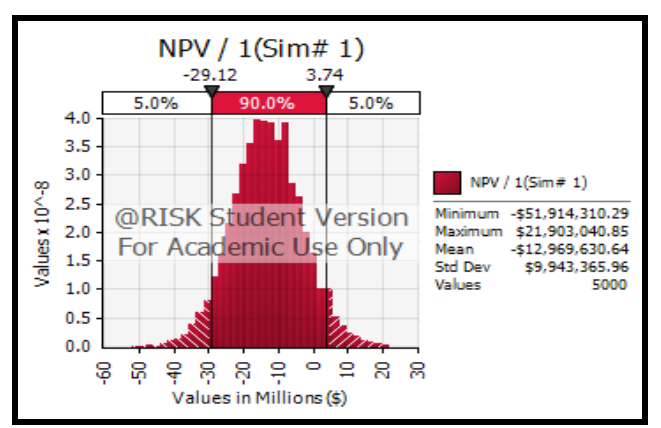

Figure 3. Model (3) SMCS Model

(without GS \& with water reduction effect level 1)

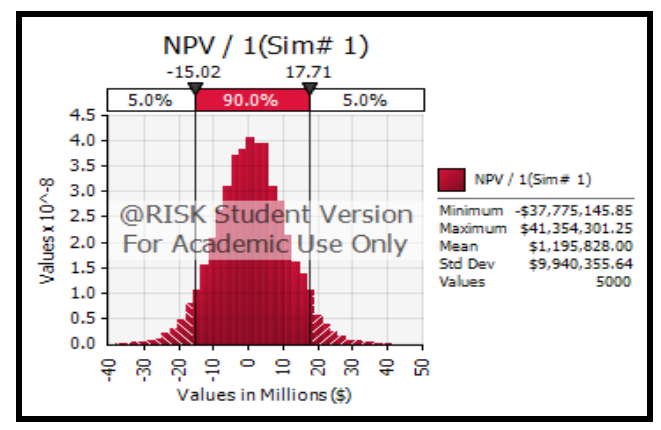

Figure 2. Model (2) SMCS Model

(with GS \& without water reduction effect)

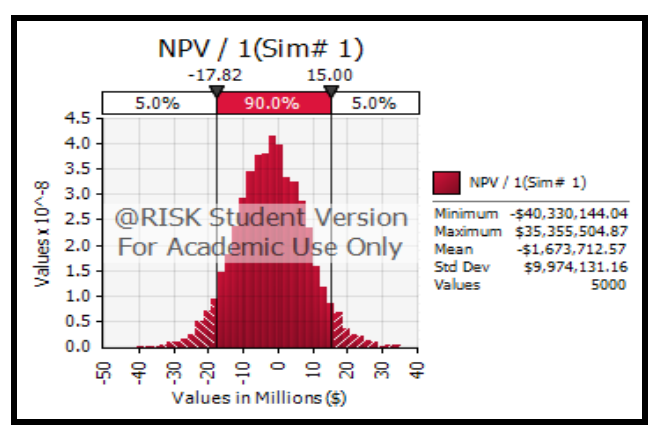

Figure 4. Model (4) SMCS Model

(with GS \& with water reduction effect level1) 


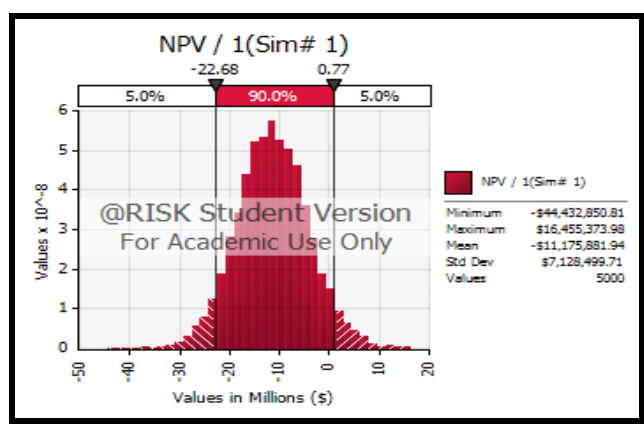

Figure 5. Model (5) SMCS Model

(without GS \& with water reduction effect - level 2)

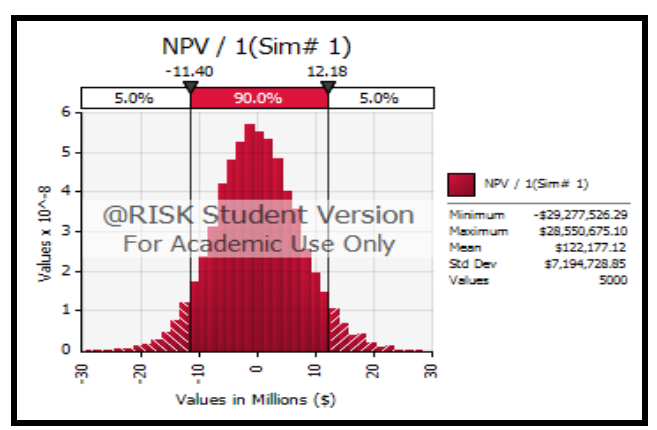

Figure 6. Model (6) SMCS Model

(with GS \& with water reduction effect-level 2)

On the other hand, we observed that the Skewness coefficient is positive and lower in models with Government subsidy (in case of no water risk), indicating that they have an elevated probability of obtaining results near the mean and symmetric distribution. But under water availability risk increase more farmers have an elevated probability of obtaining NPV below mean. However, this means Government subsidy could not mitigate and cope with underground water availability risk and water policy needs to be reformed to sustain agriculture activities at Najed area.

The kurtosis coefficient for every model is larger than 3, and we have a leptokurtic distribution that indicates that the probability distribution of the model have a narrow peak (a high probability than a normally distributed variable of values near the mean) with Government subsidy program and fat tails (a higher probability than a normally distributed variable of extreme values) especially for model (4) with Government subsidy. It is means Government subsidy will not mitigate underground water risk if no underground water recharge.

The cost of uncertainty of the project is high as shown in Figure 5 and estimated of R.O. 44.42 Million with 95\% confidence level. However, this cost determine the maximum amount of money investors and Government should be prepared to pay to obtain more hydraulic information in order to reduce project uncertainty at Najed area. As a result, more information has to be obtained regarding hydraulics and underground water availability at Najed area before distributing more lands to farmers and privet sectors at Najed area. The risk analysis also calculated the expected loss ratio which measures expected loss of the project. The study reveals that expected loss has been reduced with Government subsidy program. It also indicates project without Government subsidy program are totally exposed to risk.

\section{Conclusion}

The main task of project evaluation is to estimate the future values of the projected variables such as crop yield and other main and key variables which effect NPV and IRR of the project. The project analyst utilizes information available regarding a specific event of the past to predict a possible future outcome of the same or a similar event. Under such circumstance conventional project evaluation approach is not recommended and dynamic simulation analysis is the appropriate methodology to incorporate risk and uncertainty.

In traditional methods, we can select the project with only the greater expected NPV and IRR, but it will often lead us to suboptimal decisions as the expected return on investment (NPV) of a decision quite often carries a high degree of uncertainty with interrelated dynamics.

The use of dynamic simulation analysis and underground water risk analysis in this study did not gave a single value of NPV but gives a range of values and allocate probability of all possible expected NPV and IRR. The prospective investor and Government are therefore provided with a complete risk/return profile of the project and this will enhance investment decision.

The cost of uncertainty of the project is high. As a result, more information has to be obtained regarding hydraulics and underground water availability at Najed area before distributing more lands to farmers and privet sectors at Najed area.

The project risk analysis using Monte Carlo Simulation technics shows that the project probability distribution of NPV is completely below the zero in case of sever water shortage. The expected loss ratio of model (5) is 0.73 which means that the project is totally exposed to risk. 
The Government grant of 11.26 Million Rials are given to Najed Project to be used in project infrastructure. This grant increased project viability in case of low risk of water availability areas, but with high risk of underground water at the new developed area at Najed more Government subsidy supports are needed to mitigate risk.

New water policy needs to be reformed and adjusted to cope with risk inherit the project. Moreover, Najed Project needs to be reformed and redesigned to suit the investor requirement and achieve project sustainability.

\section{References}

Alkaraan, F., \& Northcott, D. (2006). Strategic capital investment decision-making: A role for emergent analysis tools? A study of practice in large UK manufacturing companies. The British Accounting Review, 38, 149-173. http://dx.doi.org/10.1016/j.bar.2005.10.003

Asian Development Bank. (2002). Handbook for integrated risk analysis in the economic analysis of projects. Manila, Philippines.

Botterud, A., \& Korpas, M. A. (2007). A stochastic dynamic model for optimal timing of investments in new generation capacity in restructured power systems. International Journal of Electrical Power and Energy Systems, 29, 163-174. http://dx.doi.org/10.1016/j.ijepes.2006.06.006

David, T. H. (2004). Using quantitative risk analysis to support strategic decisions neighbourhood of Z. "1 Published in Consult GEE Executive Briefings in Business Risk Management, Thomson GEE, London UK.

Gill, R. C. (2002). A stochastic feasibility study of Texas ethanol production: Analysis of Texas State Legislature ethanol subsidy. Unpublished M.S. thesis, Department of Agricultural Economics, Texas A\&M University, College Station, Texas.

James, W. R., Brian, K. He., Joe, L. O., \& Chope, G. R. (2007). Including Risk in Economic Feasibility Analyses: The Case of Ethanol Production in Texas. Journal of Agribusiness, 25(2), 115S132. Agricultural Economics Association of Georgia.

Monacciani, F. (2011). Risk assessment for development projects: An integrated approach. Journal of Applied Sciences, 11(4), 743-747. http://dx.doi.org/10.3923/jas.2011.743.747

Omer, E. (2008). Uncertainty assessment for the evaluation of net present value of a mineral deposit. Master of Science Thesis submitted to The Graduate School of Applied and Natural Sciences of Middle East Technical University, Ankara, Turkey.

Qiu, L. G. (2001). Development of risk analysis models for decision-making in project management. PhD Thesis submitted to School of the Built Environment, Napier University, Edinburgh, UK.

Quiroga, S., Fernandez-Haddad, Z., \& Iglesias, A. (2010). Risk of water scarcity and water policy implications for crop production in the Ebro Basin in Spain. Hydrology and Earth System Sciences Discussions Journal, 7, 5895-5927. http://dx.doi.org/10.5194/hessd-7-5895-2010

Savvakis, C. S. (1994). Risk analysis in investment appraisal. Project Appraisal Journal, 9(1), 3-18. http://dx.doi.org/10.1080/02688867.1994.9726923

Wang, S. Q. (1998). Evaluation and competitive tendering of power plant project in china. Journal of $\begin{array}{lllll}\text { Construction } \quad \text { Engineering } & \text { Mand } 333-341 .\end{array}$ http://dx.doi.org/10.1061/(ASCE)0733-9364(1998)124:4(333)

Water Science and Technology Association, and Omani Government-Ministry of Regional Municipalities and Water Resources. (2010). Water sustainability in GCC countries - The Need for a Socio-Economic and Environmental Definition. WSTA 9th Gulf Water Conference, Muscat, Sultanate of Oman.

\section{Copyrights}

Copyright for this article is retained by the author(s), with first publication rights granted to the journal.

This is an open-access article distributed under the terms and conditions of the Creative Commons Attribution license (http://creativecommons.org/licenses/by/3.0/). 